\title{
Perbandingan Estimasi Radar Cuaca Dopler Baron Terhadap Data Observasi Kejadian Hujan Di Kota Kupang
}

\author{
Ni Putu Nonik Prianti ${ }^{a *}$, Roddialek Pollo ${ }^{b}$, Judi K. Nasjoro ${ }^{b}$, Sulton Kharisma ${ }^{c}$ \\ a Program Studi Ilmu Lingkungan, Pasca Sarjana, Universitas Nusa Cendana Kota Kupang, Provinsi Nusa Tenggara \\ Timur \\ ${ }^{b}$ Dosen di Program Studi Ilmu Lingkungan, Pasca Sarjana, Universitas Nusa Cendana Kota Kupang, Provinsi Nusa \\ Tenggara Timur \\ ${ }^{c}$ Prakirawan di BMKG El Tari Kupang, Provinsi Nusa Tenggara Timur
}

*Email: niputunonikp@gmail.com

Abstract

Diterima (received) 8 Januari 2020; disetujui (accepted) 29 Juni 2020; tersedia secara online (available online) 1 Agustus 2020

\begin{abstract}
Radar is able to provide information about extreme weather observations in the form of heavy rain, so it is important to find the level of accuracy of the radar in providing extreme weather information. So that with accurate data disaster mitigation can be done by creating an early warning system using radar data in order to minimize the impact that will occur. Comparative analysis of the estimated rainfall events on the radar with surface observation data shows a good level of accuracy, but the blankness of the data on the radar due to damage thus influences the decision making of the forecasters when providing extreme weather information quickly to the public. By knowing the radar accuracy level is quite good in estimating rain events, BMKG can provide weather information in the form of appropriate early warning so that people can anticipate extreme weather events
\end{abstract}

Keywords: Accuracy; Extreme Weather; Rain; Radar

\begin{abstract}
Abstrak
Radar mampu menyediakan informasi tentang pengamatan cuaca ekstrim berupa hujan lebat, untuk itu penting untuk mencari tingkat keakuratan dari radar dalam memberikan informasi cuaca ekstrim. Sehingga dengan data yang akurat dapat di lakukan mitigasi bencana dengan membuat sistem peringatan dini menggunakan data radar agar dapat meminimalkan dampak yang akan terjadi. Analisis perbandingan estimasi kejadian hujan pada radar dengan data observasi permukaan meunjukkan tingkat akurasi yang baik, tetapi kosongnya data pada radar akibat kerusakan sehingga mempengaruhi pengambilan keputusan prakirawan ketika memberikan informasi cuaca ekstrim secara cepat ke masyarakat. Dengan mengetahui cukup baiknya tingkat keakuratan radar dalam mengestimasi kejadian hujan, BMKG dapat memberikan informasi cuaca berupa peringatan dini yang tepat agar masyarakat dapat mangantisipasi kejadian cuaca ekstrim
\end{abstract}

Kata Kunci: Akurasi; Cuaca Ekstrim; Hujan; Radar

\section{Pendahuluan}

Diantara parameter iklim, curah hujan (presipitasi) merupakan salah satu parameter terpenting dalam bidang meteorologi khususnya di Indonesia sebagai salah satu daerah tropis. Curah hujan merupakan salah satu parameter cuaca yang sangat penting dalam kegiatan observasi permukaan. Alat pengukur hujan yang biasa digunakan adalah tipe observatori, kelemahan alat ini adalah pengukuran hanya dilakukan setiap tiga jam di stasiun pengamatan. Curah hujan yang berlebihan pada suatu lokasi dapat menyebabkan banjir dimana merupakan salah satu bencana yang kerap melanda Indonesia sehingga telah

doi: https://doi.org/10.24843/blje.2020.v20.i02.p01

(C) 2019 by the authors; Content from this work may be used under the terms of the Creative Commons Attribution 3.0 licence. Any further distribution of this work must maintain attribution to the author(s) and the title of the work, journal citation and DOI. Published under licence by Udayana University, Indonesia. 
menjadi perhatian secara nasional oleh pemerintah. Bencana banjir menyebabkan banyak korban kehilangan nyawa dan harta benda. Keseriusan pemerintah menanggulangi bencana banjir dengan dibentuknya Badan Penanggulangan Bencana Nasional (BPBN) sebagai salah satu badan yang mempunyai peran dalam penanggulangan bencana di Indonesia.

Radar cuaca adalah salah satu instrument meteorologi yang secara efektif dapat mengamati fenomena - fenomena atmosfer yang terjadi pada skala meso/mesoscale (Houze, 1993). Kemampuan yang dimiliki radar cuaca antara lain mendeteksi awan, mendeteksi pergerakan awan, mendeteksi sebaran presipitasi, mendeteksi intensitas presipitasi, mendeteksi badai guntur, bahkan pada beberapa jenis radar cuaca dapat digunakan untuk mendeteksi kecepatan dan arah angin (vertikal dan horizontal). Akibat kemampuannya mendeteksi intensitas presipitasi, maka data radar cuaca merupakan salah satu data acuan yang dapat digunakan memprediksi bencana alam seperti banjir, tanah longsor, dan puting beliung (Zakir, Sulistya, \& Khotimah, 2010). Sampai akhir ini radar merupakan data yang umum yang digunakan sebagai sumber data dalam operasional pembuatan dan prakiraan jangka pendek dari hujan lebat. Sebab alat tersebut dapat mendeteksi dan memonitor hujan sepanjang waktu. Meskipun radar menyediakan cakupan pengamatan spasial yang cukup luas, akurasi dari pengukuran laju hujan masih tetaplah memiliki kekurangan akibat beberapa sumber error

Informasi cuaca sangat penting dalam kehidupan makhluk hidup,untuk dapat mengetahui informasi cuaca tersebut kita bisa mendapatkan informasi cuaca lewat BMKG. BMKG adalah instansi yang bertugas untuk memberikan Informasi cuaca. Sebagai prakirawan BMKG wajib untuk memberikan Informasi cuaca, karena seorang prakirawan memiliki peranan penting dalam memprakirakan dan memberikan informasi cuaca kepada masyarakat, agar masyarakat bisa lebih waspada dalam menghadapi cuaca ekstrem saat ini. Sehingga dalam hal ini prakirawan harus mengetahui keadaan cuaca yang terjadi di wilayah kita yang dapat mengganggu aktifitas kehidupan makhluk hidup, misalnya keadaan cuaca atau bisa disebut kejadian present weather (WW) seperti hujan dan guntur karena kejadian present weather ini sangat mengganggu aktifitas makhluk hidup, apalagi jika kejadiannya seperti hujan disertai Guntur yang memiliki intensitas sedang hingga lebat. Sehingga untuk mengetahui terjadinya present weather tersebut diperlukan alat bantu untuk mengamati present weather seperti Radar cuaca

Penelitian yang dilakukan berkaitan dengan validasi antara data pengamatan permukaan dan estimasi radar sudah banyak dilakukan. Penelitian yang dilakukan oleh Adam dan Lettenmaier serta Ciache (2003) dan Constantinescu dkk (2007) mendapatkan bahwa hasil estimasi radar hampir selalu overestimate terhadap curah hujan yang tertakar bergantung kepada intensitas dari hujan tersebut. (Adam J.C., 2003)

Dari latar belakang di atas penulis ingin meneliti keakuratan data radar dimana Badan Meteorologi, Klimatologi dan Geofisika (BMKG) menggunakan persamaan hubungan Z dan R Marshall - Palmer untuk memperoleh estimasi curah hujan yang dideteksi radar cuaca. Namun terdapat beberapa kejadian yang estimasi curah hujan radar cuacanya tidak sesuai dengan curah hujan pengamatan Sinoptik. Radar mampu menyediakan informasi tentang kejadian hujan, untuk itu penulis mencoba untuk mencari tingkat keakurasian dari radar tersebut dalam memberikan informasi hujan. Disini penulis mencoba untuk menganalisis tingkat akurasi data radar yang dibandingkan dengan data observasi. Sehingga penulis dapat mengetahui sampai dimana tingkat akurasi atau kemampuan radar dalam membaca kejadian hujan pada saat kejadian. Sehingga dengan data yang akurat dapat di lakukan mitigasi bencana dengan membuat sistem peringatan dini menggunakan data radar agar dapat meminimalkan dampak yang akan terjadi.

\section{Metode Penelitian}

\subsection{Lokasi dan Rancangan Penelitian}

Lokasi penelitian berdasarkan cakupan radar dalam pembuatan sistem peringatan dini yaitu wilayah Kota Kupang dan Kabupaten Kupang. 
Metode yang digunakan dalam tulisan ini adalah penelitian kuantitatif dimana penelitian ini menekankan pada aspek pengukuran data radar dan data hujan secara objektif dalam pembuatan suatu sistem peringatan dini. Ada beberapa metode yang digunakan dalam penelitian kuantitatif ini yaitu:

a. Metode komparatif dengan memverifikasi data curah hujan pada radar yang telah dikumpulkan dengan data curah hujan hasil pengkuran observasi kemudian hasilnya akan dilihat tingkat keakuratan data radar hingga memenuhi kualifikasi dalam pembuatan sistem peringatan dini.

b. Metode deskriptif merupakan suatu pencarian fakta menggunakan interprestasi yang tepat sehingga dalam penelitian ini akan dijelaskan bagaimana sistem peringatan dini dideskripsikan menggunakan data-data yang akurat.

\subsection{Data Penelitian}

Dalam penelitian ini digunakan dua jenis data sekunder yaitu data curah hujan dan data intensitas presipitasi yang dideteksi oleh radar cuaca yang merupakan suatu data yang diperoleh menggunakan ketentuan mengenai hubungan antara faktor reflektivitas radar $(Z)$ dan intensitas presipitasi (R) di Stasiun Meteorologi Klas II El Tari Kupang. Data curah hujan yang diperoleh dari hasil pengamatan sinoptik pada Stasiun Meteorologi Klas II El Tari. Dimana data yang diambil adalah data pada saat musim hujan yaitu bulan November 2018 - Maret 2019.

\subsection{Teknik Pengolahan data}

Teknik pengolahan dari dua data sekunder memiliki cara yang berbeda. Pertama, data curah hujan observasi pada bulan November tahun 2018 hingga bulan Maret tahun 2019 diambil dari buku ME 48 dimana langsung dilhat kapan terjadinya hujan kemudian diolah pada Microsoft Excel. Sedangkan data radar diolah pada PC khusus aplikasi radar. Langkah-Langkah Generate Data Radar Baron Kupang dari Archive

1. Pastikan kabel LAN warna biru terkoneksi

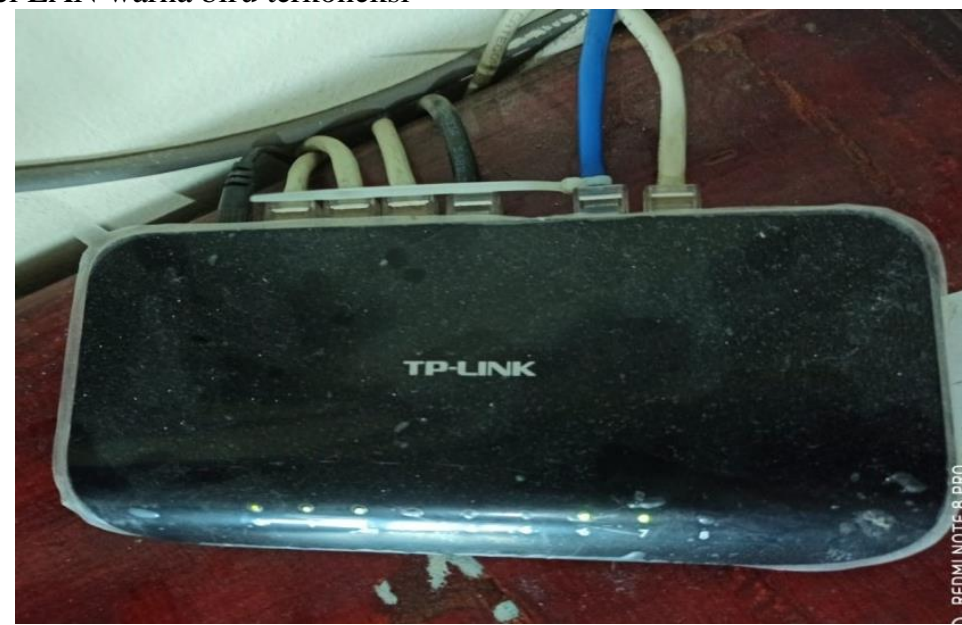

Gambar 1. Langkah ke-1 teknik pengolahan data radar

2. Kemudian di PC FCT 04 di aplikasi Radar Control di bagian kanan ada tabel System Processes. Klik Kanan matikan MuranDel dan MuranWatchdog. 


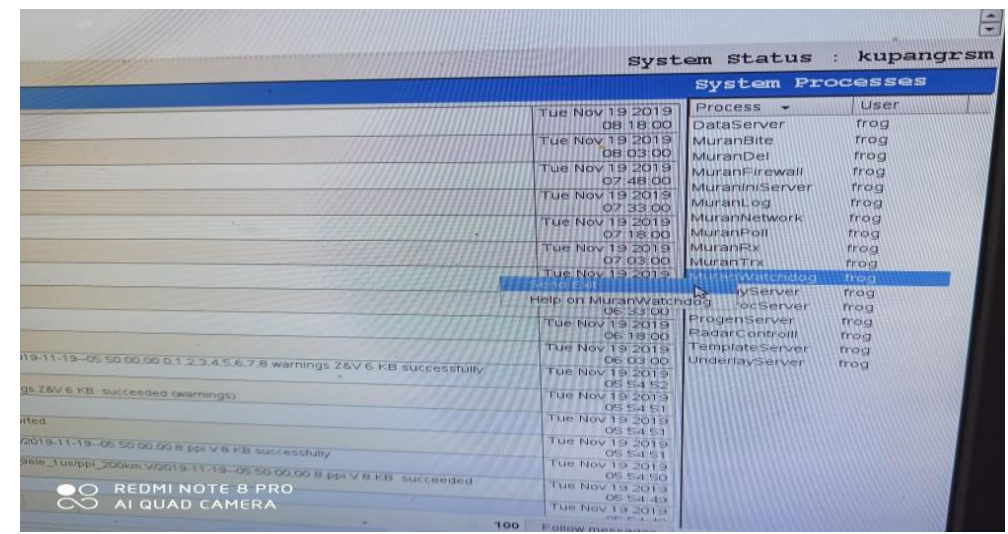

Gambar 2. Langkah ke-2 teknik pengolahan data radar

3. Pindah ke PC FCT 05 utk memilih archieve data radar. Biasanya PC nya di lock, user nya cupay pass nya cupay 123

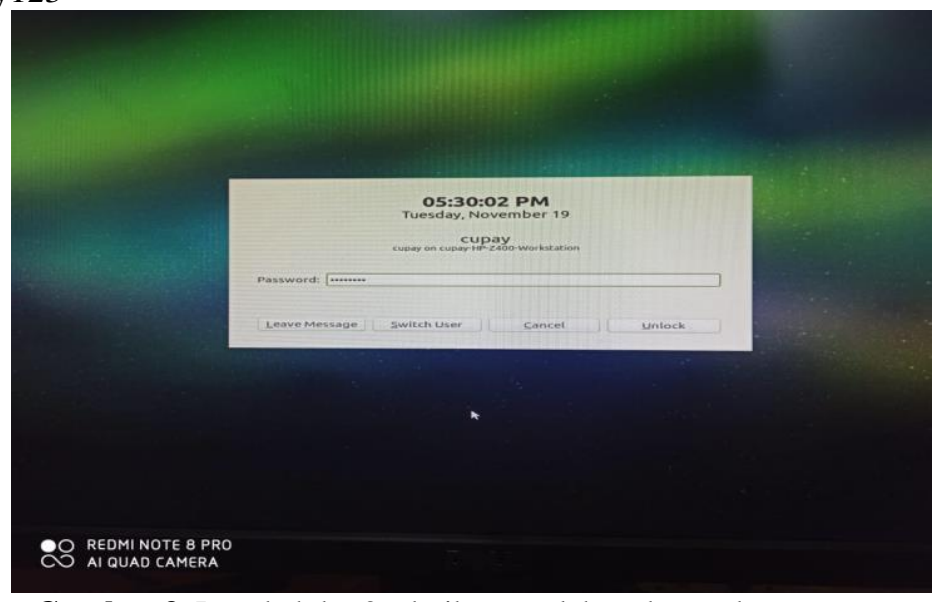

Gambar 3. Langkah ke-3 teknik pengolahan data radar

4. Klik cupay's home atau my computer nya, kemudian ketik alamat direktori nya sftp://172.21.47.123/opt/muranxx3/muran/data/kupangfrog/200km_15km_9ele_1us (ini folder share LAN nya)

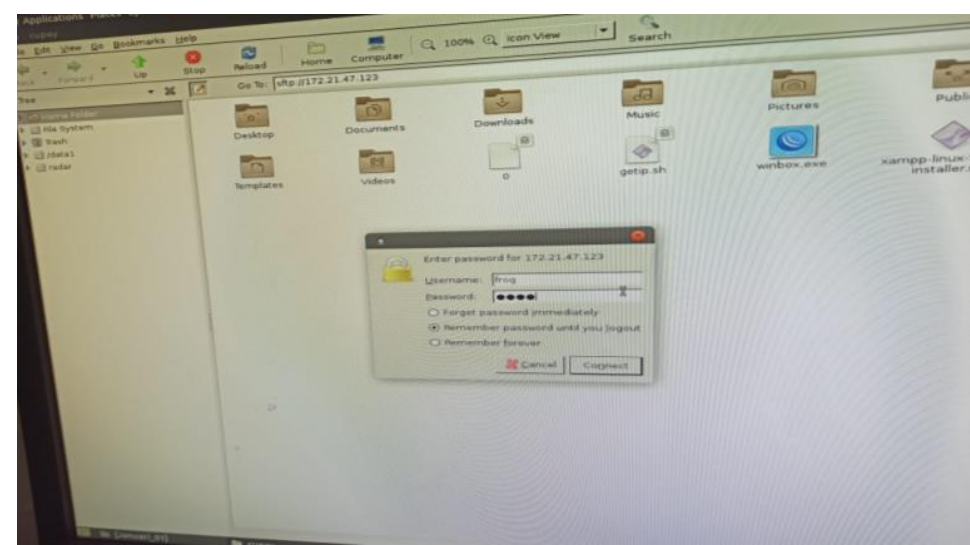

Gambar 4. Langkah ke-4 teknik pengolahan data radar 
5. Folder datanya di /media/cupay/radar/Data Radar, pilih dan copy ke folder langkah no 4 tadi

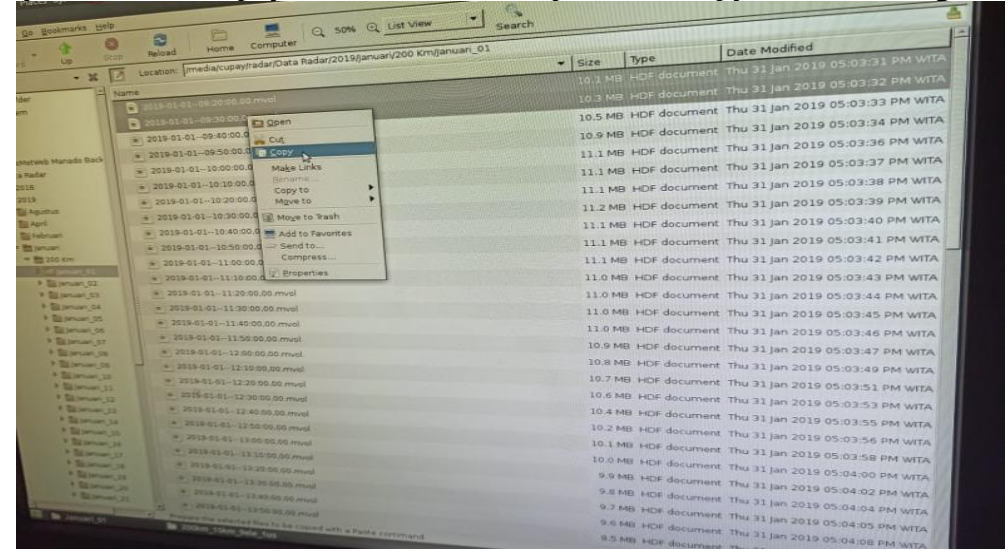

Gambar 5. Langkah ke-5 teknik pengolahan data radar

6. Setelah sudah di copy kembali kePC FCT, klik kanan di System Processes pada Data Server $>$ Reload

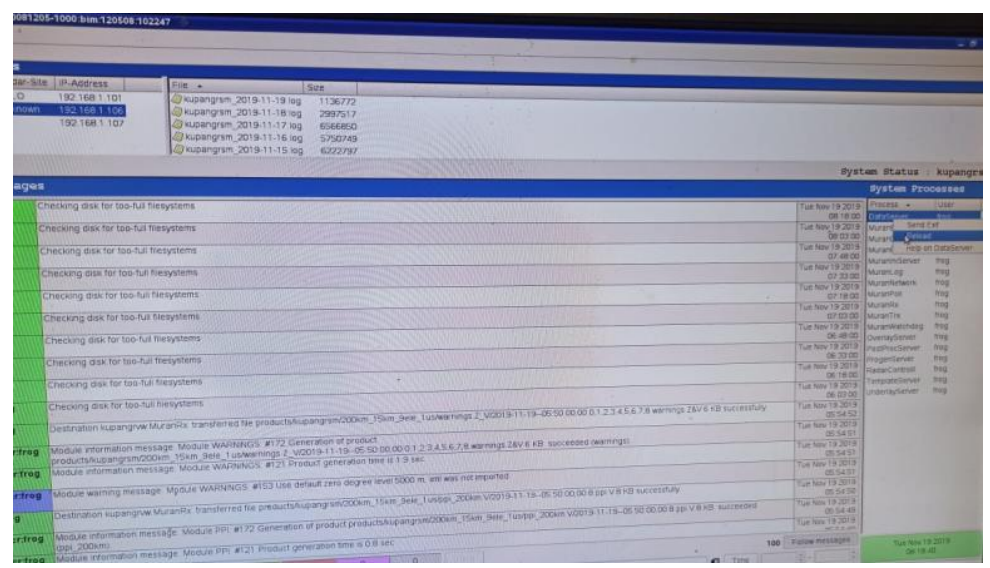

Gambar 6. Langkah ke-6 teknik pengolahan data radar

7. Ke tabel kiri cari archieve generation>pilih kupang rsm>kupang generation volume $2>$ set tanggal> all stages> generate

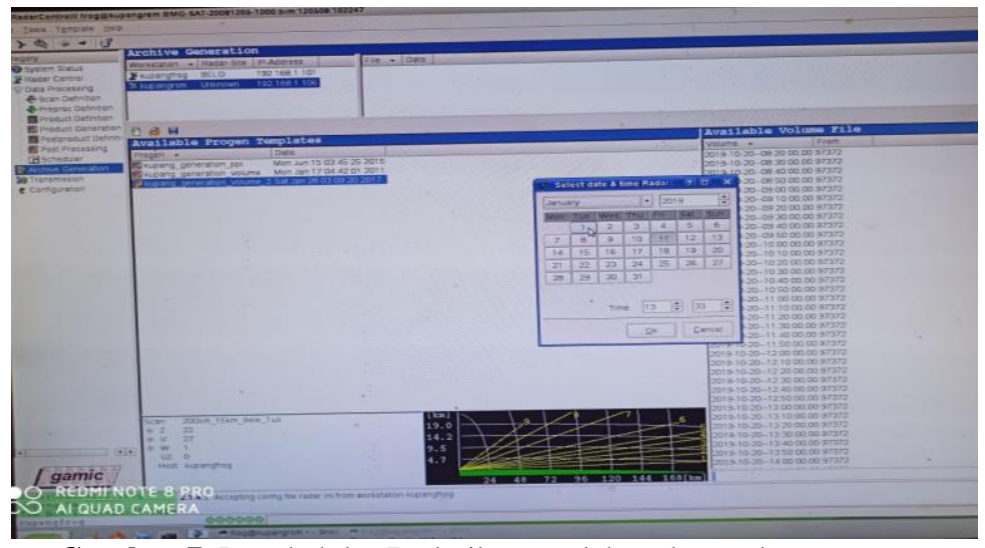

Gambar 7. Langkah ke-7 teknik pengolahan data radar 
8. Analisis di PC sebelahnya

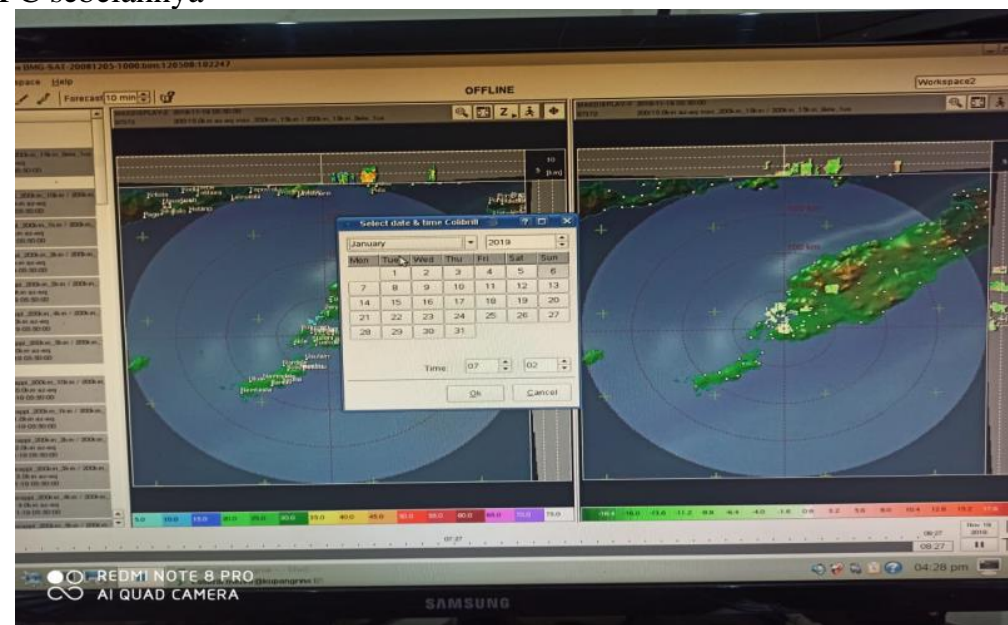

Gambar 8. Langkah ke-8 teknik pengolahan data radar

9. Setelah selesai pastikan kabel Lan dilepas dan proses langkah no 2 dikembalikan dengan cara buka terminal terus ketik MuranDel dan kemudian MuranWatchdog

\subsection{Teknik Analisa Data}

Produk data radar dapat dikategorikan sebagai data yang bersifat dikotomous (terjadi atau tidak terjadi). Tabel Kontingensi adalah salah satu metode yang dapat digunakan untuk mengetahui kualitas dari suatu data yang bersifat dikotomous, dengan metode ini dapat diketahui nilai akurasi, bias, POD ataupun FAR dari suatu sistem prakiraan. Suatu sistem prakiraan yang baik akan memiliki nilai akurasi yang baik (memenuhi suatu kriteria), tidak bias dan dapat mengukur estimasi secara benar

Tabel 1. Kontingensi (Sagita, 2014)

\begin{tabular}{|c|c|c|c|c|}
\hline \multicolumn{2}{|c|}{ FREKUENSI } & \multicolumn{2}{c|}{ OBSERVASI } & \multirow{2}{*}{ JML } \\
\cline { 3 - 4 } \multicolumn{2}{|c|}{} & YES & NO & \\
\hline \multirow{2}{*}{ RADAR } & YES & $\mathrm{a}$ & $\mathrm{b}$ & $\mathrm{a}+\mathrm{b}$ \\
\cline { 2 - 5 } & NO & $\mathrm{b}$ & $\mathrm{d}$ & $\mathrm{c}+\mathrm{d}$ \\
\hline \multicolumn{2}{|c|}{ JML } & $\mathrm{a}+\mathrm{c}$ & $\mathrm{b}+\mathrm{d}$ & $\mathrm{n}=\mathrm{a}+\mathrm{b}+\mathrm{c}+\mathrm{d}$ \\
\hline
\end{tabular}

Tabel diatas adalah bentuk dari tabel kontingensi, dimana notasi a menyatakan apabila data radar mengatakan ya (terjadi hujan) dan observasi juga mengatakan ya (terjadi hujan), notasi b menyatakan data radar mengatakan ya (terjadi hujan) sedangkan observasi mengatakan tidak (tidak terjadi hujan), notasi c menyatakan data radar mengatakan tidak (tidak hujan) dan observasi mengatakan ya (terjadi hujan), dan notasi d menyatakan baik data radar dan observasi mengatakan tidak hujan.

a) Akurasi $=(1)$

Akurasi menunjukkan semua bagian dari estimasi yang benar. Nilai akurasi dari 0 hingga 1 dan nilai 1 adalah nilai sempurna.

$$
\text { Akurasi }=(\mathrm{a}+\mathrm{d}) / \mathrm{n}
$$


b) BIAS $=(2)$

Bias mengukur perbandingan frekuensi estimasi area yang terjadi hujan terhadap observasi area yang terjadi hujan. BIAS < 1 menunjukkan underestimate dan BIAS $>1$ menunjukkan overestimate.

$$
\text { BIAS }=(a+b) /(a+c)
$$

c) $\mathrm{POD}=(3)$

POD (Probability of Detection) mengukur bagian dari observasi menunjukkan kejadian hujan yang di estimasi secara benar.

$$
\mathrm{POD}=\mathrm{a} /(\mathrm{a}+\mathrm{c})
$$

d) $\quad$ FAR $=(4)$

FAR ( False Alarm Ratio) mengukur bagian dari estimasi yang menunjukkan terjadinya hujan tapi pada kenyataannya tidak ada terjadi hujan.

$$
\mathrm{FAR}=\mathrm{b} /(\mathrm{a}+\mathrm{b})
$$

Setelah data Radar Cuaca dan data Observasi di validasi maka akan dilihat bagaimana keakuratan data radar yang digunakan sebagai pedoman pembuatan peringatan dini cuaca ekstrim. Peringatan dini cuaca ekstrim harus dibuat dan dilakukan dengan hati-hati, cermat dan dalam waktu singkat agar dapat segera didistribusikan kepada masyarakat dan stakeholder terkait.

\section{Hasil dan Pembahasan}

Data yang digunakan sebagai bahan verifikasi yaitu data hujan pada bulan November, Desember, Januari, Februari dan Maret dimana merupakan bulan hujan pada daerah Kota Kupang. Tabel berikut menunjukkan perbandingan kejadian terjadinya hujan pada data radar dengan data observasi di mana untuk nilai "0" menunjukkan tidak terjadi hujan dan nilai "1" menunjukkan terjadi hujan.

Tabel 2. Estimasi radar dan Observasi kejadian hujan pada bulan November 2018 hingga Maret 2019

\begin{tabular}{ccccccccccc}
\hline \multirow{2}{*}{ Tanggal } & \multicolumn{2}{c}{ November } & \multicolumn{2}{c}{ Desember } & \multicolumn{2}{c}{ Januari } & \multicolumn{2}{c}{ Februari } & \multicolumn{2}{c}{ Maret } \\
\cline { 2 - 10 } $\mathbf{1}$ & Radar & Observasi & Radar & Observasi & Radar & Observasi & Radar & Observasi & Radar & Observasi \\
$\mathbf{2}$ & 1 & 1 & 0 & 0 & 1 & 1 & 0 & 0 & 1 & 1 \\
$\mathbf{3}$ & 0 & 0 & 1 & 1 & 0 & 0 & 0 & 0 & 1 & 1 \\
$\mathbf{4}$ & 0 & 0 & 1 & 1 & 1 & 1 & 1 & 1 & 0 & 0 \\
$\mathbf{5}$ & 0 & 0 & 0 & 1 & 1 & 1 & 1 & 1 & 0 & 0 \\
$\mathbf{6}$ & 0 & 0 & 1 & 1 & 1 & 1 & 1 & 1 & 1 & 1 \\
$\mathbf{7}$ & 0 & 0 & 0 & 0 & 1 & 1 & 1 & 1 & 1 & 1 \\
$\mathbf{8}$ & 0 & 0 & 0 & 0 & 1 & 1 & 0 & 0 & 1 & 1 \\
$\mathbf{9}$ & 0 & 0 & 0 & 0 & 0 & 0 & 0 & 0 & 0 & 0 \\
$\mathbf{1 0}$ & 1 & 1 & 0 & 0 & 1 & 1 & 1 & 1 & 1 & 1 \\
$\mathbf{1 1}$ & 1 & 1 & 0 & 0 & 1 & 1 & 1 & 1 & 1 & 1 \\
$\mathbf{1 2}$ & 0 & 1 & 0 & 0 & 1 & 1 & 1 & 1 & 1 & 1 \\
$\mathbf{1 3}$ & 1 & 1 & 1 & 1 & 1 & 1 & 1 & 1 & 1 & 1 \\
$\mathbf{1 4}$ & 0 & 0 & 1 & 1 & 1 & 1 & 0 & 0 & 1 & 1 \\
\hline
\end{tabular}


NPN Prianti, dkk.; Perbandingan Estimasi Radar Cuaca Dopler Baron Terhadap.....

\begin{tabular}{|c|c|c|c|c|c|c|c|c|c|c|}
\hline 15 & 0 & 0 & 1 & 0 & 0 & 0 & 1 & 1 & 1 & 1 \\
\hline 16 & 1 & 1 & 1 & 1 & 1 & 1 & 1 & 1 & 1 & 1 \\
\hline 17 & 0 & 0 & 1 & 1 & 1 & 1 & 0 & 0 & 1 & 1 \\
\hline 18 & 1 & 1 & 0 & 0 & 0 & 1 & 1 & 1 & 1 & 1 \\
\hline 19 & 1 & 1 & 0 & 0 & 0 & 1 & 0 & 0 & 0 & 0 \\
\hline 20 & 1 & 1 & 0 & 0 & 1 & 1 & 1 & 1 & 0 & 0 \\
\hline 21 & 1 & 1 & 1 & 1 & 1 & 1 & 1 & 1 & 0 & 0 \\
\hline 22 & 1 & 1 & 1 & 1 & 1 & 1 & 0 & 0 & 0 & 0 \\
\hline 23 & 1 & 1 & 1 & 1 & 1 & 1 & 1 & 1 & 0 & 0 \\
\hline 24 & 1 & 1 & 1 & 1 & 0 & 0 & 1 & 1 & 1 & 1 \\
\hline 25 & 1 & 1 & 1 & 1 & 0 & 0 & 1 & 1 & 0 & 0 \\
\hline 26 & 0 & 0 & 1 & 1 & 1 & 1 & 1 & 1 & 0 & 0 \\
\hline 27 & 0 & 0 & 1 & 1 & 1 & 1 & 0 & 1 & 0 & 0 \\
\hline 28 & 0 & 0 & 1 & 1 & 1 & 1 & 1 & 1 & 1 & 1 \\
\hline 29 & 0 & 0 & 1 & 1 & 1 & 1 & & & 1 & 1 \\
\hline 30 & 0 & 0 & 1 & 1 & 0 & 0 & & & 1 & 1 \\
\hline 31 & & & 0 & 1 & 0 & 0 & & & 1 & 1 \\
\hline
\end{tabular}

Probabilitas ada atau tidaknya kejadian hujan pada observasi permukaan dan estimasi data radar pada bulan November tahun 2018 hingga bulan Maret tahun 2019 tersaji secara lengkap pada tabel 3 hingga tabel 7

Tabel 3. Tabel probabilitas bulan November 2018

\begin{tabular}{|c|c|c|c|c|}
\hline \multirow{2}{*}{ FREKUENSI } & \multicolumn{2}{c|}{ OBSERVASI } & \multirow{2}{*}{ JML } \\
\cline { 3 - 4 } \multicolumn{2}{|c|}{} & YES & NO & \\
\hline \multirow{2}{*}{ RADAR } & YES & 16 & 0 & 16 \\
\cline { 2 - 4 } & NO & 2 & 12 & 14 \\
\hline \multicolumn{2}{|c|}{ JML } & 18 & 12 & 30 \\
\hline
\end{tabular}

Tabel 4. Tabel probabilitas bulan Desember 2018

\begin{tabular}{|c|c|c|c|c|}
\hline \multirow{2}{*}{ FREKUENSI } & \multicolumn{2}{c|}{ OBSERVASI } & \multirow{2}{*}{ JML } \\
\cline { 3 - 4 } \multicolumn{2}{|c|}{} & YES & NO & \\
\hline \multirow{2}{*}{ RADAR } & YES & 18 & 1 & 19 \\
\cline { 2 - 4 } & NO & 3 & 9 & 12 \\
\hline \multicolumn{2}{|c|}{ JML } & 21 & 10 & 31 \\
\hline
\end{tabular}


Tabel 5. Tabel probabilitas bulan Januari 2019

\begin{tabular}{|c|c|c|c|c|}
\hline \multicolumn{2}{|c|}{ FREKUENSI } & \multicolumn{2}{c|}{ OBSERVASI } & \multirow{2}{*}{ JML } \\
\cline { 3 - 4 } & YES & NO & \\
\hline \multirow{2}{*}{ RADAR } & YES & 22 & 0 & 22 \\
\cline { 2 - 4 } & NO & 6 & 3 & 9 \\
\hline \multicolumn{2}{|c|}{ JML } & 28 & 3 & 31 \\
\hline
\end{tabular}

Tabel 6. Tabel probabilitas bulan Februari 2019

\begin{tabular}{|c|c|c|c|c|}
\hline \multirow{2}{*}{ FREKUENSI } & \multicolumn{2}{c|}{ OBSERVASI } & \multirow{2}{*}{ JML } \\
\cline { 3 - 4 } \multicolumn{2}{|c|}{} & YES & NO & \\
\hline \multirow{2}{*}{ RADAR } & YES & 19 & 0 & 19 \\
\cline { 2 - 4 } & NO & 3 & 6 & 9 \\
\hline \multicolumn{2}{|c|}{ JML } & 22 & 6 & 28 \\
\hline
\end{tabular}

Tabel 7. Tabel probabilitas bulan Maret 2019

\begin{tabular}{|c|c|c|c|c|}
\hline \multirow{2}{*}{ FREKUENSI } & \multicolumn{2}{c|}{ OBSERVASI } & \multirow{2}{*}{ JML } \\
\cline { 3 - 4 } & YES & NO & \\
\hline \multirow{2}{*}{ RADAR } & YES & 20 & 0 & 20 \\
\cline { 2 - 4 } & NO & 1 & 10 & 11 \\
\hline \multicolumn{2}{|c|}{ JML } & 21 & 10 & 31 \\
\hline
\end{tabular}

Tabel 8. Digunakan untuk memperoleh nilai dari analisis statistik bulan November tahun 2018 hingga bulan Maret tahun 2019 berupa akurasi, BIAS, POD dan FAR.

Tabel 8. analisis statistik bulan November tahun 2018 hingga bulan Maret tahun 2019

\begin{tabular}{ccccccc}
\hline No & Indeks & November & Desember & Januari & Februari & Maret \\
\hline $\mathbf{1}$ & Akurasi & 0.967 & 0.903 & 0.935 & 0.964 & 1 \\
$\mathbf{2}$ & BIAS & 0.929 & 0.950 & 0.917 & 0.950 & 1 \\
$\mathbf{3}$ & POD & 0.929 & 0.900 & 0.917 & 0.950 & 1 \\
$\mathbf{4}$ & FAR & 0 & 0.053 & 0 & 0 & 0 \\
\hline
\end{tabular}

Tabel 8 berisi nilai indeks perhitungan statistik dari estimasi kejadian hujan pada radar terhadap observasi permukaan. Dimana untuk nilai akurasi estimasi radar pada bulan November tahun 2018 adalah 0.967 atau $96.7 \%$ yang berarti nilai keakurasian estimasi radar pada kejadian hujan sebesar $96.7 \%$. Untuk bulan Desember tahun 2018 adalah 0.903 atau 90.3\% yang berarti nilai keakurasian estimasi radar pada kejadian hujan sebesar $90.3 \%$. Untuk bulan Januari tahun 2019 adalah 0.935 atau $93.5 \%$ yang berarti nilai keakurasian estimasi radar pada kejadian hujan sebesar 93.5\%. Untuk bulan Februari tahun 2019 adalah 0.964 atau $96.4 \%$ yang berarti nilai keakurasian estimasi radar pada kejadian hujan sebesar 96.4\%. Untuk bulan Maret tahun 2019 adalah 1 atau 100\% yang berarti nilai keakurasian radar pada kejadian hujan sebesar $100 \%$ 
Untuk nilai pada indeks BIAS pada bulan November tahun 2018 adalah 0.929, pada bulan Desember tahun 2018 adalah 0.950, pada bulan Januari tahun 2019 adalah 0.917, dan bulan Februari tahun 2019 adalah 0.950, dimana jika nilai dari indeks BIAS dibawah 1 menunjukkan underestimate dari estimasi radar. Nilai BIAS pada bulan Maret tahun 2019 sebesar 1, yang artinya estimasi radar pada bulan Maret tahun 2019 menunjukkan nilai yang sempurna.

Untuk nilai pada indeks POD pada bulan November tahun 2018 adalah 0.929 atau 92.9\%, bulan Desember tahun 2018 adalah 0.950 atau 95.0\%, bulan Januari tahun 2019 adalah 0.917 atau $91.7 \%$, bulan Februari tahun 2019 adalah 0.950 atau 95.0\%, dan pada bulan Maret tahun 2019 sebesar 1 atau 100\%, yang menunjukkan bahwa nilai tersebut adalah kejadian hujan yang di estimasi secara benar dari bulan November tahun 2018 hingga bulan Maret tahun 2019.

Untuk nilai pada indeks FAR pada bulan November tahun 2018 hingga bulan Maret tahun 2019 sebesar 0 atau $0 \%$ sehingga nilai tersebut menunjukkan kejadian hujan yang di estimasi radar sudah benar jika dibandingkan dengan data observasi dengan tingkat kesalahan $0 \%$. Perbedaan nilai hanya terjadi bulan Desember tahun 2018 sebesar 0.053 atau 5.3\% yang artinya hanya pada bulan ini terjadi kesalahahan dalam estimasi radar sebesar 5.3\%.

Setelah data Radar Cuaca dan data Observasi di validasi maka selanjutnya prakirawan dapat membuat peringatan dini menggunakan data radar dengan hati-hati, cermat dan dalam waktu singkat agar dapat segera didistribusikan kepada masydarakat dan stakeholder terkait.

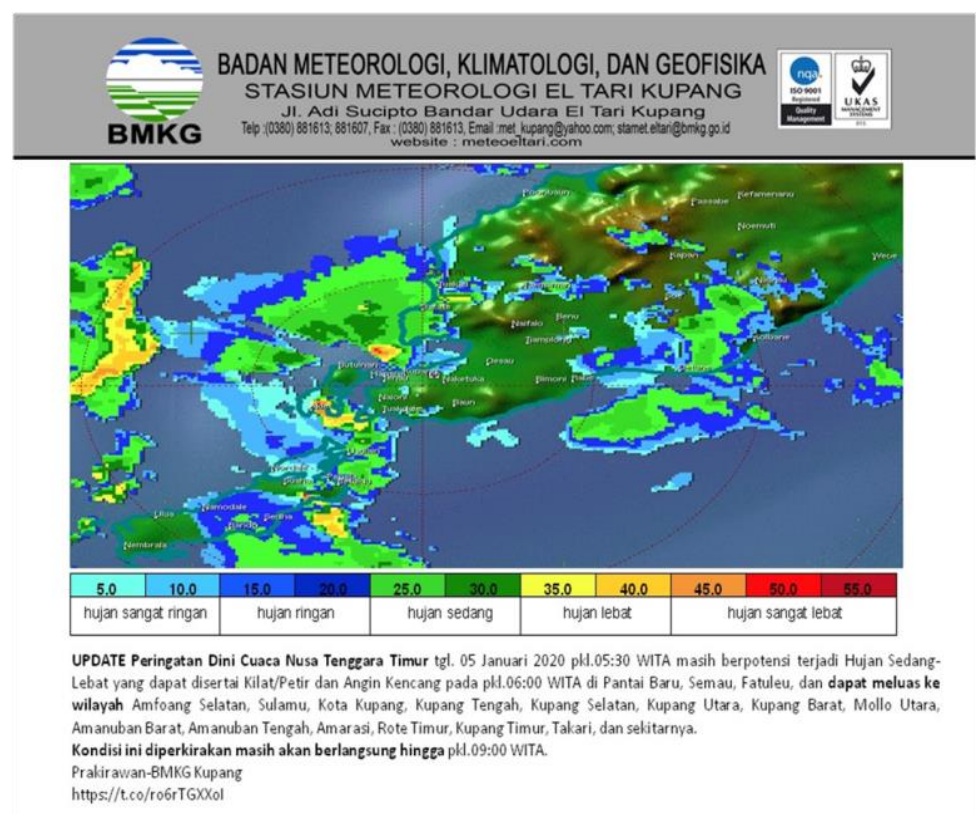

Gambar 9. Peringatan dini cuaca ekstrim yang dikeluarkan BMKG El Tari Kupang

\section{Simpulan}

Dengan melihat nilai indeks statistik dari akurasi, BIAS, POD, FAR pada bulan November tahun 2018 hingga bulan Maret tahun 2019 dapat disimpulkan bahwa tingkat akurasi radar dalam mengestimasi kejadian hujan setelah dibandingkan dengan data observasi permukaan untuk wilayah Kota Kupang sangat baik. Ini terlihat dari nilai indeks yang mendekati $100 \%$ keakuratan dimana pada empat bulan data yang di estimasi tingkat kesalahannya mencapai $0 \%$ dan hanya 1 bulan yang memiliki tingkat kesalahan 5.3\% pada bulan Desember tahun 2018 . 
Dengan mengetahui sangat baiknya tingkat keakuratan radar dalam mengestimasi kejadian hujan, sehingga prakirawan BMKG dapat memberikan informasi cuaca yang tepat kepada masyarakat agar dapat mengantisipasi kejadian cuaca ekstrim.

Salah satu kekurangan pada radar adalah beberapa datanya ada yang kosong disebabkan kerusakan radar sehingga mempengaruhi pengambilan keputusan prakirawan ketika memberikan informasi cuaca ekstrim secara cepat ke masyarakat.

\section{Daftar Pustaka}

Adam J.C., L. D. (2003). Adjustment of global gridded precipitation for systematic bias. Journal of Geophysical Research, 108.

BMKG. (2010). Peraturan Kepala BMKG Nomor 009 tahun 2010 tentang Prosedur Standar Operasional Pelaksanaan Peringatan Dini Cuaca Ekstrim, Pelaporan dan Diseminasi Informasi Cuaca Ekstrim . Jakarta: BMKG.

Denis, M., \& Dwi, S. (n.d.). Alat Pengukur Curah Hujan. Retrieved from https://id.scribd.com/doc/1680471.

Herujono. (2000). Modul Pendahuluan Radar Cuaca . Jakarta: BPLP-AMG.

Houze, R. (1993). Cloud Dynamics. California: Academics Press Inc.

https://id.wikipedia.org/wiki/Kabupaten_Kupang.(n.d.).

https://id.wikipedia.org/wiki/Kota_Kupang. (n.d.).

Mercado, R. (2016). Design of wireless sensor networks using embedded Programmable System-on-Chip

(PSoC) as applied to community-based flood early warning system (CBFEWS). In Advances in Electrical, Electronic and Systems Engineering (ICAEES) (pp. pp.214-223). Internastional Conference on IEEE.

Nuryanti, J. T., \& A.Warsito. (2018). Pemetaan Daerah Rawan Banjir Dengan Penginderaan Jauh dan Ssitem Informasi Geografis di Kecamatan Kupang Timur kabupataten Kupang Provinsi Nusa Tenggara Timur. Jurnal Fisika Sains dan Aplikasinya, Volume 3, No.2.

Rinehart, R. (1997). RADAR for Meteorologists. Columbia: Rinehard Publishing.

Sagita, N. (2014). Perbandingan Estimasi Curah Hujan Radar C-band dengan Data Observasi Permukaan Pada Bulan Desember 2013. Manado: BMKG.

Soetardjo. (1979). Weather Radar. Jakarta: BMKG.

Susandi, A., Tamamadin, M., \& Nurlela, I. (2008). Fenomena Perubahan Iklim dan Dampaknya Terhadap Ketahanan pangan di Indonesia. Seminar NasionalPadi .

Wirjohamidjojo, S. (2006). Awan dan Inti Kondensasi. Jakarta: BMKG.

Zakir, A., Sulistya, W., \& Khotimah, K. (2010). Perspektif Operasional Cuaca Tropis. Jakarta: BMKG. 